\title{
FAMÍLIA E CLÃ NAS NARRATIVAS PATRIARCAIS E NA LITERATURA PROFÉTICA: UM BREVE COMENTÁRIO
}

\section{FAMILY AND CLAN IN THE PATRIARCHAL NARRATIVES AND IN THE PROPHETIC LITERATURE: A BRIEF COMMENTARY}

Suzana Chwarts*

\section{Resumo}

Este artigo busca destacar, através de análise estrutural e de terminologias específicas do original hebraico, questões de gênero na criação do homem e da mulher, assim como seus papeis como esposo e esposa, pai e mãe na família nuclear e estendida, como exemplificado nas narrativas patriarcais e na Torá. São analisados os processos que envolvem a conformação do beit av bíblico e do clã, bem como os princípios subjacentes a sua estrutura, como a linhagem patrilinear, a sucessão agnática e suas dinâmicas específicas - a segmentação das linhagens e casamentos endogâmicos. O código clânico da vingança e resgate são apresentados a fim de se contextualizar o emprego da instituição do goel pelos profetas de Israel - suas relações de parentesco e atribuições - na formação de sua teologia da Salvação. Baseados nas obrigações inalienáveis do goel para com seu clã, os profetas instilaram, com sucesso, no povo de Judá a certeza de que Deus os redimirá do sofrimento e das tribulações.

Palavras-chave: Bíblia Hebraica, Família Bíblica, Clã Bíblico, Casamento Endogâmico, Redenção de Israel.

\begin{abstract}
This article seeks to highlight, through structural analysis and specific terminologies of the original Hebrew, gender issues in the creation of man and woman, and their roles as husband and wife, father and mother in the nuclear and the extended family, as exemplified in the patriarchal narratives and in the law of the Torah. The processes involving the conformation of the biblical beit $a v$ and clan as well as the principles underlying its structure, such as

\footnotetext{
* Professora de Bíblia Hebraica na Faculdade de Filosofia, Letras e Ciências Humanas da Universidade de São Paulo.
} 
patrilineal lineage and agnatic succession, and its specific dynamics, such as the segmentation of lineages and endogamous marriage, are analyzed. The clan code of revenge and rescue is put on relief in order to contextualize the employment of the goel institution by the prophets of Israel - its kinship relations and attributions - in the shaping of their theology of Salvation. Based on the inalienable obligations of the goel to his clan, the prophets successfully instilled in the people of Judah the certainty that God will redeem them from their suffering and tribulations.

Keywords: Hebrew Bible, Biblical Family, Biblical Clan, Endogamous Marriage, Redemption of Israel. 


\section{O casal primordial}

O termo "bom" [tov] é uma importante palavra-guia na Bíblia Hebraica. Independentemente do contexto, sempre remete o leitor-ouvinte ao relato inicial da criação em Gênesis 1: e viu Deus que era bom. ${ }^{1}$

A palavra, que denota sanção e aprovação divinas, ocorre sete vezes no primeiro capítulo de Gênesis, com ênfase especial para o sexto dia de criação, quando viu Deus tudo quanto fizera, e eis que era muito bom (Gênesis 1:31). Uma só vez Deus diz: "não é bom" [lo tov]. Em Gênesis 2:18, lê-se: "não é bom que o homem seja só" 2 .

A fim de cumprir o número de seus dias - estipulado em 120 anos - e a finalidade de sua vida, o homem deve ter uma contraparte que lhe corresponda, e a relação que os une reflete a natureza carnal-espiritual dos humanos: "o homem adere à sua mulher, e são uma só carne" (Gênesis 2:24)

A forma verbal daváq (que traduzo como "aderir" e cujo sentido literal é "grudar", “colar”) é empregada na Bíblia para designar a aderência do justo a Deus. O emprego desse verbo alça o ato sexual à esfera espiritual e o torna sublime, não apenas porque restaura a unidade primeva do gênero humano, mas, sobretudo, porque celebra sua união espiritual com Deus. Obviamente, não há menção alguma à reprodução. Davaq denota simplesmente amor e devoção. Assim, caminham os humanos pela vida aos pares. O par passa a ser o unitário, a medida ideal.

O verbo empregado por Deus ao criar a mulher significa "construir", "edificar" $(\text { waybên })^{3}$, e essa terminologia será empregada pelas matriarcas estéreis, com o intuito de designar sua própria edificação como ser social no seio da sua família. Sara, em Gênesis 16:2, diz a Abraão: Eis que o Senhor me tem impedido de ter filhos; toma, pois, a minha serva; porventura terei filhos [ybanê] por meio dela. E ouviu Abrão a voz de Sarai. Raquel, em Gênesis 30:3, propõe: Eis aqui minha serva Bila; recebe-a por mulher, para que ela dê à luz sobre os meus joelhos, e eu deste modo tenha filhos [ybanê] por ela.

\footnotetext{
${ }^{1}$ As citações bíblicas em itálico são do Antigo Testamento Poliglota (São Paulo: Edições Vida Nova e Sociedade Bíblica do Brasil, 2003). As citações bíblicas entre aspas são de minha própria tradução, a partir do hebraico original. No presente artigo, adoto a transliteração fonética do hebraico simplificada e dirigida ao público leigo.

${ }^{2} \mathrm{O}$ argumento de Caim ("quem me encontrar me matará"), condenado a ser errante sobre a terra, demonstra que o homem não pode subsistir sozinho. Para Caim - o primeiro assassino, o primeiro fratricida -, o mundo está habitado por assassinos em potencial, como ele.

${ }^{3} \mathrm{O}$ verbo empregado para criar o humano é yatsár, que significa "criar a partir de uma matéria" - a qual, sabemos, é o pó da terra.
} 
É ao se deparar com a mulher [isháh] que o homem reconhece a si próprio como ish [homem], sendo estabelecido um vínculo de espelho entre ambos.

Os caminhos do homem e da mulher continuam paralelos no Éden, como também na punição à transgressão aí cometida: a mulher é punida com a multiplicação de suas gravidezes e esforços [itsvonêkh]; com esforço [étsev], ela dará à luz filhos. O homem também é punido com o esforço: com esforço [itsavón], ele comerá todos os dias de sua vida. ${ }^{4}$

Essa nova situação contrasta radicalmente com a essência do Éden, cujo cerne é a ausência de qualquer esforço. No Éden, Deus concede ao humano fartura, beleza e descanso.

O desejo da mulher [teshuqáh] que a levou a transgredir também é punido: será direcionado, por sua vez, ao homem, que a controlará - "ao seu homem seu desejo [tshuqatêkh], e ele o governará" (Gênesis 3:16).

Mas é a possibilidade de desejarem viver para sempre, provando do fruto da árvore da vida, que faz com que Deus os lance para fora do Éden: [...] Assim que não estenda a mão e tome também da árvore da vida, e coma, e viva eternamente (Gênesis 3:22-23).

$\mathrm{Na}$ concepção bíblica, esse par e sua função complementar - na qualidade de pai e mãe - são fundamentais na edificação do núcleo familiar.

O Decálogo apresenta uma injunção que não figura nos códigos legais da Antiguidade: Honra teu pai e tua mãe, para que se prolonguem os teus dias na terra que $H^{\prime}$, teu Deus, te $d a^{5}$ (Êxodo 20:12). Esse é um decreto aos filhos de Israel, o qual, com uma inversão surpreendente (tua mãe e teu pai), também se encontra em Levítico 19:3, texto em que se emprega o verbo temer (o mesmo empregado em referência ao temor a Deus), com o sentido de respeitar e reverenciar: Revenciará [tiraú] cada um a sua mãe e a seu pai.

A ideia de incluir a mãe e posicioná-la no mesmo patamar do pai é singular da Bíblia Hebraica. Ademais, nenhuma outra cláusula do Decálogo prevê uma recompensa.

O profeta Ezequiel inclui o desrespeito aos pais entre os pecados mais graves cometidos pela geração do Primeiro Templo, punida com a destruição e o exílio: [...] No meio de ti, se despreza o pai e a mãe [...] (Ezequiel 22:7).

A lei pune com a morte o filho que atacar ou amaldiçoar seu pai e sua mãe (Ex 21:1517, Lv 20:9, Dt 27:16; Ez 22:7) e, em Deuteronômio 21:18-21, um filho rebelde - que se

\footnotetext{
${ }^{4} \mathrm{O}$ radical das duas palavras hebraicas etsev e itsavon (yod, tsadiq, vet) é o mesmo. A primeira palavra significa "esforço" e também "tristeza".

${ }^{5}$ Deuteronômio 5:16: Honra teu pai e tua mãe, como Y, teu Deus, te ordenou, para que se prolonguem os teus dias e para que te vá bem na terra que Y, teu Deus, te dá.
} 
recusa a obedecer tanto ao pai quanto à mãe - deve ser entregue por ambos às autoridades competentes. O pai e a mãe são igualmente responsáveis pela virgindade pré-nupcial da filha, e a infração desse costume desonra a casa do seu pai ${ }^{6}$.

O profeta Eliseu, antes de seguir Elias em sua missão profética, tem apenas um pedido: despedir-se de seus pais: [...] Deixa-me beijar a meu pai e a minha mãe e, então, te seguirei. (1Reis 20:20).

Os primeiros conselhos da literatura sapiencial, na Bíblia Hebraica, enaltecem os ensinamentos do pai e da mãe:

Filho meu, ouve o ensino [mussár] de teu pai e não deixes a instrução [torah] de tua mãe; porque serão diadema de graça para tua cabeça e colares, para teu pescoço. (Provérbios $1: 8-9)$

Filho meu, guarda o mandamento [mitzváh] de teu pai e não deixes a instrução [torah] de tua mãe; ata-os perpetuamente ao teu coração, pendura-os ao pescoço; quando caminhares, isso te guiará; quando te deitares, te guardará; quando acordares, falará contigo; porque o mandamento é lâmpada e a instrução luz, e as repreensões da disciplina são o caminho da vida. (Provérbio 6: 20-23)

É digno de nota o fato de a mitzváh ser a lâmpada e a torah, a luz, visto ser a lâmpada o instrumento que irradia luz. Já o termo mussár define o ensinamento do pai como disciplina, e não como inspiração. Em suma, essas passagens abrem uma janela através da qual observamos a dinâmica da família bíblica no que concerne à educação: o ensino da mãe tem valor transcendental, enquanto o do pai tem caráter pragmático e normativo.

A terminologia familiar, no entanto, hierarquiza as relações conjugais, uma vez que o marido é cognominado baál ou adôn ${ }^{7}$ (ambos os termos significam "senhor"), e a esposa, ishá beulát baál [mulher assenhoreada de senhor].

O termo bêit $a v^{8}$ (literalmente, "casa do pai”) designa o núcleo familiar estendido ${ }^{9}$. O bêit $a v$ é patriarcal e patrilinear e está estruturado a partir de laços de consanguinidade e

\footnotetext{
${ }^{6}$ Deuteronômio 22:13: Se um homem casar com uma mulher, e depois de coabitar com ela, a aborrecer e lhe atribuir atos vergonhosos e contra ela divulgar má fama, dizendo: casei com esta mulher e me cheguei a ela, porém não a achei virgem, então, o pai da moça e sua mão tomarão provas de sua virgindade e as levarão aos anciãos da cidade, à porta. O pai da moça dirá aos anciãos: dei minha filha por mulher a este homem; porém ele a aborreceu; e eis que lhe atribui atos vergonhosos, dizendo: não achei virgem a tua filha; todavia, eis aqui as provas da virgindade da minha filha. E estenderão a roupa dela diante dos anciãos da cidade, os quais tomarão o homem e o açoitarão e o condenarão a 100 siclos de prata, e o darão ao pai da moça, porquanto divulgou má fama sobre uma virgem de Israel.

Ela ficará sendo sua mulher, e ele não poderá mandá-la embora durante sua vida. Porém, se isto for verdade, que não se achou na moça a virgindade, então a levarão à porta da casa de seu pai e os homens da cidade a apedrejarão até que morra, pois fez loucura em Israel, prostituindo-se na casa de seu pai; assim, eliminarás o mal do meio de ti.

${ }^{7}$ Adon é empregado também pelos filhos, filhas e servos.

${ }^{8}$ A família estendida é também padrão na Mesopotâmia. Nas cartas de Mari, do século 18 AEC, ela é designada pela expressão bit abim.
} 
afinidade: inclui pai, mãe, filhos e filhas não casados, filhos casados com suas esposas e filhos, viúvas e órfãos aparentados, servos, escravos e gerím [estrangeiros] sob a proteção do patriarca.

Os "saídos da coxa de Jacó", 10 que imigram juntamente com ele ao Egito, perfazem três gerações, totalizando 70 pessoas (Gênesis 46:27).

Eliezer, servo de Abrão, é designado pelo patriarca como ben-mésheq bêití [filho de minha casa] (Gênesis 15: 2).

Impera, na família bíblica, a ideologia numérica, uma vez que a família estendida também constitui um modo de recrutamento social. Portanto, quanto mais numerosa, mais poderosa e independente é a família. Esses são atributos expressivos não apenas na esfera doméstico-econômica, mas, principalmente, na esfera política, no que se refere a questões de guerra e resgate.

Abraão é capaz de recrutar 318 "homens treinados nascidos em sua casa" [yelidêi beitô] para resgatar Ló, sua família e seus bens (Gênesis 14:14).

Cumprindo a ordem divina de circuncidar todos os membros masculinos de sua família, Abrão circuncida todos os homens da sua casa, tanto os escravos nascidos nela como os comprados por dinheiro ao estrangeiro (Gênesis 17:27).

A ideologia numérica inclui também a esfera das posses materiais, sendo que o radical $k v d$ designa, simultaneamente, peso e honra: pesado em posses [kavêd] e honra [kavód]. A ideia que subjaz a essa terminologia é a de poder.

Agar, pesada em sua gravidez e imbuída da honra de portar o filho do patriarca, olha com desprezo para Sarai, sua senhora estéril. O narrador bíblico declara que "Sarai torna-se leve aos seus olhos", jogando habilmente com os sentidos de peso/honra não enunciados, mas implícitos na gravidez da serva.

A riqueza dos patriarcas é repetidamente enfatizada nas narrativas. Na Bíblia Hebraica, formar uma família equivale a edificar uma casa. As implicações de consanguinidade e

\footnotetext{
${ }^{9}$ Em algumas instâncias, figura também o termo beit 'em [casa da mãe], que, provavelmente, designa a visão da criança sobre o seu lar. Trata-se de uma expressão da intimidade de sua relação com a mãe, pois é sabido que as crianças coabitam com ela até serem desmamadas (geralmente, aos três anos de idade) e mesmo depois, uma vez que é a mãe que se ocupa da educação das crianças pequenas e das meninas até a idade do casamento (p. ex., Gn 24:28: [...] E Rebeca correu e contou aos da casa de sua mãe [beit 'imah] todas essas coisas. Cf. também Rt 1:8 e Ct 3:4, 8:2). Crianças pequenas eram educadas por suas mães (Pr 1:8, 6: 20), enquanto os pais disciplinavam os meninos (Ex10:2, 12:26; 13:8; Dt 4:9, 6:7, 20-25, 32:7,46; Pr 1:8, 6:20).

10 "Coxa", nesse contexto, é um eufemismo para o órgão reprodutor masculine. Portanto, "saídos da coxa", bem como o fruto "das entranhas", implica uma relação de consanguinidade.
} 
solidariedade implícitas no termo beit av se estendem a ponto de toda a nação de Israel ser designada como a Casa de Israel, no sentido corporativo, ou seja, beit israêl.

$\mathrm{Na}$ esfera do beit av, a autoridade do patriarca é absoluta, e é ele que determina questões de sucessão, herança, culto, vida e morte dos membros da casa.

Judah, contrariando o costume do levirato, segundo o qual a viúva sem filhos deve desposar o irmão do falecido, para que seu nome não se apague de Israel, ordena a Tamar, sua nora, que habite como viúva na casa de seu pai e, quando ouve que esta está grávida, ordena a sua morte, sem saber ainda que o genitor é ele mesmo (cf. Gênesis 38:11,24).

Abrãao deu tudo o que possuía a Isaque. Aos filhos de sua segunda esposa, Keturah (cognominados, pejorativamente, no texto, de bnei hapilagshím [filhos do concubinato]), deu presentes e os afastou do lar patriarcal, enviando-os ao Oriente (em Gênesis 25:6).

Jacó declara a José que seus dois filhos, Manassés e Efraim, serão considerados como seus próprios filhos e altera, deliberadamente, o princípio da primogenitura, abençoando, com a mão direita, a Efraim e declarando-o primogênito, apesar dos protestos de seu pai: [...] Os teus dois filhos que te nasceram na terra do Egito são meus [...]. O seu irmão menor será maior do que ele, e sua descendência será uma multidão de nações [...] (Gênesis 48:5,19).

\section{Linhagens patrilineares e o processo de segmentação}

A casa patriarcal está alicerçada sobre quatro princípios básicos: autoridade, descendência, sucessão e residência. A autoridade é patriarcal; a descendência, patrilinear e agnática; a sucessão prioriza o primogênito; e a residência é patrilocal.

Essa estrutura desencadeia tensões variadas no seio da família, que resultam, no jargão da antropologia social, na segmentação da linhagem em linhagem senior e sublinhagens, como o tronco de uma árvore e suas ramificações (FOX, 1967, p. 122-123).

Apenas o primogênito dá continuidade à linhagem de seu pai. Os outros irmãos inauguram linhagens aparentadas. Isaque dá continuidade à linhagem de Abraão como seu sucessor e legatário de todos os seus bens. Ismael e os filhos de Keturah são afastados do lar patriarcal e fundam suas próprias linhagens, apesar de permanecerem zêra' (termo que designa, simultaneamente, sêmen, semente, descendência) de Abraão.

Pressões de ordem econômica e territorial também fazem com que as linhagens se segmentem, e, na Bíblia Hebraica, esses processos sociais são narrados como sagas de 
separação familiar, embora sejam ressaltados os fatores econômicos que determinam tais separações.

Por exemplo, Ló, sobrinho patrilateral de Abraão, que vive sob sua proteção e deslocase conjuntamente com ele, acumula tantos bens que seus pastores entram em conflito com os do seu tio:

Ló, que ia com Abrão, também tinha rebanhos, gado e tendas; e a terra não podia sustentá-los, para que habitassem juntos, porque eram muitos os seus bens; de sorte que não podiam habitar um na companhia do outro. Houve contenda entre os pastores de gado de Abrão e os pastores de Ló... E disse Abrão a Ló: Não haja contenda entre mim e ti e entre os meus pastores os teus pastores, porque somos parentes chegados [ki anashím achím anáchnu ${ }^{11}$.

[...] Peço-te que te apartes de mim; se fores para a esquerda, irei para a direita; se fores para a direita, irei para a esquerda. (Gênesis 13:5-9)

Ló parte, então, para o Oriente, para o vale do Jordão, que era todo bem regado, como o Jardim de Deus, como a terra do Egito, como quem vai para o Zoar (Gênesis 13:10).

Depois da morte de Isaac, Jacó permanece detentor da bênção do primogênito, sendo, portanto, seu herdeiro e legatário de todos os seus bens. Esaú, deserdado, afasta-se de seu irmão:

[...] Levou Esaú suas mulheres, e seus filhos, e todas as pessoas de sua casa, e seu rebanho, e.todo o seu gado, e toda propriedade, tudo o que havia adquirido na terra de Canaã; e se foi para outra terra, apartando-se de Jacó, seu irmão. Porque os bens deles eram muitos para habitarem juntos; e a terra de suas peregrinações não os podia sustentar por causa de seu gado. (Gênesis 36:6-7)

A dinâmica da segmentação de linhagens funda o clã que, na Bíblia hebraica, consiste em uma associação de casas patriarcais unidas pelo princípio de um ancestral comum, vínculos de solidariedade, relações de filiação (consanguinidade) e afiliação. A coesão do clã é vital para assegurar a identidade e a continuidade do grupo, principalmente quando ele se acha encravado no meio de grupos mais numerosos e poderosos ${ }^{12}$.

O clã é designado como mishpachá na Bíblia, mas esse termo pode também indicar divisões, parentes, família e até tribo.

\footnotetext{
${ }^{11}$ Fórmula de afinidade agnática. O termo "irmão" era liberalmente empregado na Bíblia, sem implicitar relação de consanguinidade. Ló chama aos sodomitas "irmãos"; e Jacó, aos pastores de Haran.

${ }^{12}$ A priori, o clã, como grupo corporativo de descendência, não se define pelo vínculo consanguíneo, mas apenas pelo princípio do ancestral comum, seja ele real, seja fictício. O clã constitui um subgrupo da tribo, a qual é, na Bíblia, comumente chamada de shevet ou matteh.
} 
[...] Então Moisés e Arão tomaram estes homens, que foram designados pelos seus nomes. E, tendo ajuntado toda a congregação no primeiro dia do mês segundo, declararam a descendência deles, segundo as suas famílias, segundo as casas de seus pais [waytyaldú 'al mishpachotám levêit avotám], contados nominalmente, de vinte anos para cima, cabeça por cabeça. (Números 1:17-19)

Nessa passagem, fica claro que mishpacháh designa o clã, enquanto beit 'av corresponde ao núcleo familiar estendido.

\section{A instituição do matrimônio}

Por fim, o pilar essencial de qualquer agrupamento humano que almeja manter a sua identidade cultural, bem como suas propriedades e coesão, é o casamento endogâmico.

O casamento ideal, na Bíblia Hebraica, é o monogâmico, entre linhagens de um mesmo clã e, preferivelmente, entre parentes consangüíneos. Fortalecem-se, assim, os laços de consanguinidade e os acertos econômicos que estruturam a instituição do matrimônio. O casamento poligâmico, no entanto, era permitido e praticado. Note-se, porém, que Abraão e Isaque têm uma só esposa e que Jacó pretendia casar-se apenas com Raquel.

É Abraão quem enuncia as leis positivas e negativas sobre o matrimônio, ao enviar seu servo Eliezer à casa patriarcal de seu irmão Nacor, na Mesopotâmia, com o intuito de buscar uma esposa para seu filho: [...] Não tomarás uma mulher para meu filho entre as filhas do canaaneu no meio em que habito [...], mas onde é minha terra, onde foi meu nascimento, irás tomar uma mulher para meu filho (Gênesis 24:3-4).

$\mathrm{O}$ elemento da consanguinidade nas narrativas matrimoniais dos patriarcas funciona também como um veículo efetivo para se projetar um velado juizo de valor sobre as personagens: enquanto Isaac e Jacó, herdeiros da promessa divina, casam-se endogamicamente com suas primas consanguíneas, Rebeca, Lea e Raquel, seus irmãos deserdados, Ismael e Esaú, que formam linhagens correlatas, casam-se exogamicamente, uma atitude que enfatiza sua desqualificação como possíveis herdeiros de Abraão e Isaque e evidencia sua inaptidão para gerar a linhagem ancestral de Israel.

Ismael morou no deserto de Faran, e sua mãe lhe escolheu uma mulher da Terra do Egito (Gênesis 21:21). Já Esaú, cujo traço principal é a obtusidade, desqualifica-se duplamente por meio de seus matrimônios. Primeiro, ele desposa mulheres hititas: Quando 
Esaú completou 40 anos, tomou ele como mulheres Judite, filha de Beeri, o heteu, e Basemat, filh de Elon, o heteu. Elas se tornaram uma amargura para Isaac e Rebeca (Gênesis 26:34).

Quando percebe que o casamento exogâmico desagrada a seus pais, investe em um casamento endogâmico e casa-se justamente com sua prima-irmã, Mahalat, filha de Ismael, excluindo-se duplamente, assim, da herança legítima de Israel:

Esaú viu que o pai havia abençoado a Jacó e o tinha enviado a Padan-Aram para lá tomar mulher, e, abençoando-o, lhe dera esta ordem: "não tomes uma mulher entre as filhas de Canaã". E Jacó obedecera a seu pai e sua mãe e partira para Padan-Aram. Esaú soube que as filhas de Canaã eram malvistas por seu pai Isaac; foi à casa de Ismael e tomou como mulher - além daquelas que já possuía - Mahalat, filha de Ismael, filho de Abraão e irmã de Nebaiot. (Gênesis 28:6-9)

Esse é um exemplo admirável de ironia bíblica. Em termos históricos, esse matrimônio aponta para algum tipo de associação militar entre ismaelitas e edomitas contra Israel, a qual é mencionada no Salmo 83:6.

O casamento exogâmico se tornará paradigma de enganação e armadilha na Bíblia Hebraica e será severamente condenado nos expedientes de Êxodo e Deuteronômio: [...] não farás aliança com elas $[. . .]^{13}$, não contrairás matrimônio com elas, não darás tua filha a um de seus filhos, nem tomarás uma de suas filhas para teu filho [...], para que não caias numa armadilha [...] (Deuteronômio 7:2-3,25). A base racional dessa injunção se acha em Deuteronômio 7:3-4: Pois deste modo seu filho se afastaria de mim para servir a outros deuses, e a cólera de Deus se inflamaria contra vós, exterminando-te rapidamente.

A assimilação temida parece ter-se tornado uma realidade no tempo de Neemias: [...] $V i$ também, naqueles dias, que judeus [hayehudím] haviam-se casados com mulheres ashdoditas, amonitas e moabitas. Seus filhos falavam meio ashdodita e não sabiam falar judaico [yehudit], mas a língua de seu respectivo povo (Neemias 13:23-24).

Os textos acima expressam uma posição clara quanto aos matrimônios indesejados, mas quem seria a noiva protótipo em Israel? Em minha opinião, Rebeca.

Na descrição de Eliezer do seu encontro com Rebeca num poço de Arám Naharáym, são enunciados os requisitos ideais de uma noiva bíblica:

\footnotetext{
${ }^{13}$ Referência às nações erradicadas por Deus da Terra Prometida, como consequência de seus pecados, que poluíam a terra, reduto divino.
} 
[...] Não havia ele acabado de falar, eis que saiu Rebeca, filha de Batuel, filho de Milca, mulher de Nahor, irmão de Abraão, trazendo seu cântaro sobre o ombro. A moça era muito bela, jovem [betulá, ou seja, em idade de casar-se], nenhum homem a tinha conhecido [ou seja, virgem]. (Gênesis 25:15-16)

Os dados genealógicos da noiva em potencial são descritos com precisão, de modo a comprovar a relação de consanguinidade entre os futuros noivos: Rebeca é filha de Melca, esposa oficial de Nacor, irmão de Abraão, e seus atributos são desejáveis, sendo sua virgindade indispensável.

No livro de Gênesis, a instituição do clã bíblico e suas dinâmicas constituem o fio condutor do ciclo narrativo patriarcal. Já na história posterior da Terra de Israel, o clã parece ter perdido sua força como referencial. É comum encontrar entre os historiadores bíblicos a suposição de que o advento da realeza, a criação de uma estrutura burocrática e a ascensão de uma classe burguesa associada à crescente urbanização de Israel e Judá seriam os fatores responsáveis pelo esgarçamento de seu tecido social.

De fato, 10 tribos de Israel desapareceram da história em virtude da conquista assíria e sua política de exilar os habitantes do país e assentar, em seu território, gentes de outros domínios, como se lê nos anais do rei assírio Sargão II, citados na obra Israel e Judá: textos do Antigo Oriente Médio:

Os tamudi, os ibadidi, os marsimani, os hayapa, árabes longínquos que habitavam o deserto, que não conheciam nem chefe nem governador e que não entregavam suas rendas a nenhum rei, eu os abati, pondo minha confiançaa em Assur, meu senhor; deportei os que restavam e os fiz habitar na cidade de Samaria. (1985, p. 71)

Esse depoimento extrabíblico encontra paralelo em 2Reis 17:24-33, onde se enumeram povos que foram assentados na Samaria: Depois o rei da Assiria trouxe gente de Babilonia, de Cuta, de Ava, de Hamate e de Sefarvaim, e a fez habitar nas cidades de Samaria em lugar dos filhos de Israel; e eles tomaram Samaria em herança, e habitaram nas suas cidades.

No entanto, quando os exilados na Babilônia retornam a Jerusalém, ainda são nominados de acordo com suas tribos e clãs: [...] Habitaram, pois, em Jerusalém alguns dos filhos de Judá e dos filhos de Benjamim. Dos filhos de Judá: Ataías, filho de Uzias, filho de Zacarias, filho de Amarias, filho de Sefatias, filho de Maalale, dos Filhos de Perez (Neemias 11:4-8). 


\section{O Deus gô̂l}

Os profetas sedimentaram suas ideias de redenção e salvação de Israel nas tradições do clã, adicionando a elas uma camada adicional de sentido, para adaptá-las às exigências de seu próprio tempo. Esse é o caso do vingador de sangue [goêl], umas das mais importantes instituições do clã bíblico.

Apesar de, na literatura profética, o termo ser empregado para designar a ação salvadora de Deus, sua origem reside na esfera jurídica da estrutura clânica, de modo que o compreender em sua acepção original torna-se fundamental para apreender o senso de compromisso e obrigatoriedade que essa linguagem imprime à ação divina.

O termo goêl é empregado em conexão com o direito da família e reflete o princípio israelita da importância de se preservar a unidade do clã. Aparentemente, ele não possui cognatos nas línguas semitas e é comumente traduzido como redimir.

Nos códigos de retribuição do clã, o goêl tem atribuições de vingador, como se lê em Números 35:19: O vingador do sangue matará ao homicida; ao encontrá-lo, o matará.

$\mathrm{Na}$ qualidade de redentor, o goêl é o parente mais próximo na linhagem agnática, que deve atuar com vistas a evitar uma ruptura na descendência e na propriedade do clã. Conforme Levítico 25: 25-26 (e também em Jeremias 32:6), o goêl deve evitar a alienação da propriedade de seus parentes, adquirindo-a.

Infere-se do relato de Rute 4:4 que é também sua obrigação evitar a alienação de uma esposa viúva que pertence ao seu clã e casar-se com ela, suscitando descendência para o morto. Em qualquer circunstância, o goêl deve redimir "seu irmão" da escravidão, como ensina Levítico 25:47. O israelita entende que as obrigações do goêl para com seu clã são eternas e insubstituíveis.

A imagem de Deus como redentor [goêl] de Israel se acha presente em Êxodo 6:6-7, que representa a ação divina por meio de uma vasta terminologia interconectada ao plano ontológico (salvação, libertação, resgate, aliança): Eu sou o Senhor e vos farei sair de debaixo das cargas do Egito, vos libertarei de sua escravidão, e vos resgatarei [g'l] com mão estendida e com grandes julgamentos. Tomar-vos-ei por meu povo, e serei vosso Deus.

Em Isaías 35:9, dois termos da esfera jurídica do clã são empregados para designar os retornados da Babilônia: Assim voltarão os que foram libertados por Deus. A tradução não permite ver que, nessa afirmação, há duas categorias que se complementam: os que caminham 
redimidos [we halkhu ge'ulim] e os libertados de Deus [peduyei $h^{\prime}$ ]. Ambas as categorias se referem àqueles que voltarão do exílio, purificados pelo sofrimento e aptos a operar em prol da restauração de Israel $^{14}$.

Os profetas e os salmistas exploraram as fortes conotações dessas instituições jurídicas e aplicaram-nas ao pensamento religioso, de modo a reafirmar a certeza na ação salvadora divina, ressaltando o fato de que a redenção obrigatória é um elemento fundacional da ordem social de Israel, cuja origem é divina.

Apesar de os termos serem esvaziados de seu sentido jurídico estrito, sua carga ontológica carrega o senso de obrigatoriedade original. O discurso profético assegura ao povo que existe uma relação íntima entre ele e Deus e que sua redenção é uma certeza: [...] Mas, agora, diz Deus, aquele que te criou, ó Jacó, aquele que te modelou, ó Israel; não temas, porque eu te resgatarei; chamei-te pelo teu nome: tu és meu. (Isaías 43:1-3)

A enorme ênfase do vínculo de parentesco entre Deus e Israel é evidenciada não apenas pela terminologia salvadora, mas pela de consanguinidade, amor, compromisso e aliança.

O profeta Isaías, no capítulo 46:3-5, evoca a relação maternal, marcada pelo amor e pela misericórdia:

Vós a quem carreguei desde o seio materno [rechem]; a quem levei desde o berço [...], eu vos conduzirei, eu vos carreguei e vos salvarei. (Isaías 46:3-5)

Por acaso uma mulher se esquecerá da sua criancinha de peito? não se compadecerá ela dos filhos de seu ventre? ainda que as mulheres se esquecessem, eu não me esqueceria de ti; eis que te gravei nas palmas de minhas mãos. (Isaías 49:15-16)

É significativo o fato de o sentimento que exprime a relação entre Deus e Israel, nessas passagens, ser a misericórdia [rachamím], termo que, em hebraico, é derivado de réchem [útero].

A imagem da relação conjugal aprofunda o significado de eleição, aliança e compromisso: [...] Porque o teu esposo será o teu criador, $h^{\prime}$ dos exércitos é seu nome, $O$ santo de Israel, teu redentor [goêl] (Isaías 54:5-8).

\footnotetext{
${ }^{14}$ Isaías desenvolve a ideia de que a salvação é imediata, sedimentada no regresso do resto de Israel [she'ar] a Sião, purificado pelo sofrimento do exílio. No "livro da Consolação de Israel" (Is 40-55), as esperanças de um fim do ciclo de opressão e início de um futuro redentor estão sendo realizadas com o retorno do exílio e a restauração do culto em Jerusalém. Também para Jeremias e Ezequiel, a ideia de redenção está vinculada à restauração e ao retorno dos exilados, uma nova geração purificada (Jr 32:37; Ez 11:17-21).
} 
O resgate é, essencialmente, um ato de amor por parte de Deus: [...] Mas porque o Senhor vos amava, e para guardar o juramento que fizera a vossos pais, o Senhor vos tirou com mão poderosa e vos resgatou da casa da servidão, do poder do Faraó do Egito (Deuteronômio 7:8).

$\mathrm{O}$ ato redentor oriundo do amor divino cria uma situação definitiva e irreversível, no tocante ao compromisso. Por sua vez, Israel também deverá agir com amor para com os escravos, destituídos e estrangeiros (Deuteronômio 15:15, 24:21-22).

Em Isaías, a redenção de Israel é eterna, assim como o amor e compaixão que Deus nutre por seu povo.

Visto que foste precioso aos meus olhos

digno de honra, e eu te amei, darei homens por ti e os povos por tua vida; não temas, porque sou contigo.

Trarei a tua descendência desde o Oriente e a ajuntarei desde o Ocidente. (Isaías 43:4-5)

[...] Desfaço as tuas transgressões como a névoa e os teus pecados como as nuvem; torna-te para mim porque eu te remi. (Isaías 44: 22)

Por breve momento te deixei, mas com grandes misericórdias torno a acolher-te; num ímpeto de indignação, escondi de ti minha face por um momento;

mas com misericórdia eterna me compadeça de ti, diz o Senhor, o teu Redentor. (Isaías 54: 7-10)

Ainda que a redenção divina tenha abrangência universal, nas profecias messiânicas de Isaías, Jeremias e Ezequiel, esta é dirigida a Israel.

O clã bíblico, como princípio de organização social, pode ter desaparecido de Israel; seus princípios e códigos, no entanto, permanecem como sustentáculo da existência espiritual judaica até os dias de hoje, fundamentando a conexão entre Deus e Israel através de vínculos indissolúveis de aliança, fidelidade e eleição. 


\section{Bibliografia}

FOX, R. Kinship \& marriage: an antropological perspective. Cambridge: Cambridge University Press, 1967.

Israel e Judá: Textos do Antigo Oriente Médio. São Paulo: Editora Paulus, 1985.

SAYÃO, L. (Ed.). Antigo Testamento Poliglota. São Paulo: Edições Vida Nova e Sociedade Bíblica do Brasil, 2003. 